\title{
RANCANG BANGUN SISTEM TRACKING JASA LAUNDRY SEPATU DI CLINIX SHOES CARE BERBASIS WEBSITE
}

\author{
Febriyan Saragih $^{\bowtie}$, Yulia Agustina Dalimunthe, Husni Lubis \\ Program Studi Sistem Informasi, Universitas Harapan, Medan, Indonesia \\ Email: riyansaragih15@gmail.com
}

DOI: $\underline{\text { https://doi.org/10.46880/jmika.Vol5No1.pp73-76 }}$

\begin{abstract}
The matter of time still being an important thing in a shoe's laundry services, because it can take a long time to get a shoes laundry. That's why it required a tracking system to checking a status from our shoes at the clinix shoes and care laundry. The making of this system uses the method, waterfall starting from requirements analysis, system design, writing program code, testing programs, implementing programs, and writing program code in a structured manner. Writing program code using PHP, MySQL database and using the framework. With Codeigniter 3 this tracking system, customers can input the receipts provided by the admin clinix shoes care, to find out the status of shoes being laundered, and in this tracking system the customer can also check rates laundry.
\end{abstract} Keyword: Tracking, Laundry, Waterfall, Framework Codeigniter.

\section{ABSTRAK}

Permasalahan waktu menjadi sangat penting dalam sebuah jasa laundry sepatu, karena banyaknya waktu yang digunakan untuk melaundry sebuah sepatu. Oleh sebab itu diperlukan sebuah sistem tracking untuk melakukan pengecekan status sepatu yang sedang dilaundry pada jasa laundry sepatu Clinix shoes and care. Pembuatan sistem ini menggunakan metode waterfall mulai dari analisis kebutuhan, desain sistem, penulisan kode program, pengujian program, penerapan program, dan penulisan kode program dilakukan secara terstuktur. Penulisan kode program menggunakan PHP, database MySQL dan juga menggunakan framework Codeigniter 3. Dengan adanya sistem tracking ini costumer dapat menginputkan resi yang diberikan oleh admin clinix shoes care, untuk mengetahui status sepatu yang sedang dilaundry, dan pada sistem tracking ini costumer juga dapat mengecek tarif laundry.

Kata Kunci: Tracking, Laundry, Waterfall, Framework Codeigniter.

\section{PENDAHULUAN}

Informasi merupakan unsur pokok yang secara implisit melekat dalam konsep pembangunan yang terencana. Walaupun peranan data dalam sebagian dekade kurang menemukan atensi, tetapi sebetulnya kebutuhan akan data serta komunikasi itu ialah perihal yang tidak kalah berartinya dari kebutuhan sandang serta pangan manusia.

Aktivitas pembangunan manapun pula hanya bisa berlangsung serta menggapai target apabila dalam tiap tahapan, perencanaan, penerapan, serta pengawasan didasarkan pada data yang mencukupi. Data memanglah diperoleh lewat aktivitas komunikasi namun yang sebetulnya yang memastikan nilai komunikasi merupakan data yang dibawa. Revolusi data, umumnya difahami selaku pergantian yang dihasilkan oleh teknologi data. 2 wujud teknologi komunikasi manusia yang terutama merupakan teknologi buat menyalurkan data serta sistem komputer modern untuk memprosesnya (Ahmad, 2012).
Perkembangan teknologi juga mempengaruh sistem informasi pada jasa laundry, sistem yang baik akan membantu perusahaan dalam pendataan barang, pembuatan laporan, dan mengelola laporan keuangan. Maka dari itu disebuah jasa laundry sepatu diperlukan sebuah sistem untuk melakukan pendataan barang agar mempermudah konsumen dalam mengetahui pengecekan status sepatu yang sedang dilaundry (Andriansyah, 2018).

Tracking merupakan aktivitas menunjukkan data benda shipper lewat sesuatu media tertentu. Tujuannya merupakan membagikan status data pengiriman benda yang diperlukan oleh shipper menimpa benda kirimannya. Aktivitas tracking ini dicoba oleh shipper, bukan oleh pihak penyedia jasa pengiriman benda, pihak penyedia jasa cuma sediakan status data pengiriman yang diperlukan oleh para shipper (Sitanggang, Magdalena, \& Martha, 2017).

Pengecekan status laundry sepatu masih dilakukan menggunakan aplikasi chatting secara 
personal atau konsumen masih harus datang langsung ke penyedia jasa laundry sepatu apakah sepatunya sudah selesai dilaundry atau belum. Oleh sebab itu dibutuhkan sebuah sistem untuk melakukan pengecekan status laundry sepatu.

Sistem yang akan dibangun nanti menggunakan framework codeigniter, CodeIgniter merupakan powerfull open source PHP framework yang mudah dipahami, dibentuk untuk PHP programmers yang memerlukan toolkit sederhana serta baik untuk membuat full- featured website applications (Blanco \& Upton, 2009). CodeIgniter ialah MVC framework yang di design untuk memudahkan penggunanya.. Framework codeigniter ini dipilih karena memiliki dokumentasi yang lengkap ini lah yang membuat peneliti ingin menggunakannya.

\section{TINJAUAN PUSTAKA}

Pada penelitian terdahulu yang berjudul Sistem Informasi Pelayanan Jasa Laundry Sepatu Pada Shoes Cleaning Majalengka, proses pengumpulan data menggunakan sumber data primer dan sekunder yaitu dengan melakukan observasi langsung dan wawancara serta menganalisis dokumen yang tersedia. Dalam pembahasannya, peneliti menggunakan metode pengembangan prototype untuk pengembangan sistem sedangkan untuk metode pendekatan sistem yang digunakan dengan metode pendekatan berorientasi objek. Dari penelitian terdahulu peneliti ingin mengembangkan sistem tracking untuk mempermudah konsumen untuk melakukan pengecekan status sepatu dalam proses laundry. Dan juga meminimalisir terjadinya overload yang menyebabkan estimasi pengerjaan melebihi waktu yang ditentukan. Berdasarkan hasil pengujian perangkat lunak dengan kasus uji sample di atas dapat di tarik kesimpulan bahwa perancangan dari perangkat lunak Sistem Informasi Pelayanan Jasa Laundry Sepatu dapat berjalan dan berfungsi dengan baik, selain itu secara fungsional perangkat lunak ini mengeluarkan hasil sesuai dengan apa yang diharapkan sebelumnya (Yulisar, 2019).

Selanjutnya pada penelitian lainnya mengenai analisis sistem informasi laundry menggunakan metode waterfall berbasis android yang bertujuan untuk merancang dan membangun sistem informasi berbasis android dengan menggunakan metode waterfall. Sistem data yang dibentuk bisa menuntaskan kasus yang berlangsung mengenai transaksi pada laundry. Sistem data ini bisa menunjang laundry dalam melaksanakan pengolahan informasi transaksi laundry secara cepat dan mudah dan menolong pelanggan buat mendapatkan data menimpa proses laundry lewat smartphone android. Sistem informasi dirancang bersumber pada tahapan yang ada pada tata cara waterfall. Sebaliknya proses pembangunan sistem data memakai aplikasi Kodular serta database Airtable (Andriansyah, 2018).

Berdasarkan penelitian terdahulu dalam membangun penerapan model waterfall pada sistem informasi layanan jasa laundry berbasis web. Perancangan sistem merupakan solusi dalam menyelesaikan permasalahan proses kerja dengan memanfaatkan kemajuan teknologi dan informasi. Dibutuhkan pemilihan metode pengembangan sistem yang efisien serta efektif sehingga kebutuhan pengguna bisa segera terpenuhi dengan informasi yang telah terkomputerisasi.

Metode pengembangan sistem yang digunakan merupakan Waterfall dengan 5 tahapan yakni analisa kebutuhan, desain sistem, pembuatan kode program, implementasi, pendukung serta pemeliharaan. Hasil riset akan menciptakan suatu sistem informasi layanan laundry berbasis web yang membagikan kemudahan dalam melaksanakan proses transaksi.

\section{METODE PENELITIAN}

Metode pengembangan sistem yang digunakan ialah metode System Development Life Cycle (SDLC) model waterfall. Metodologi ini mencakup beberapa fase ataupun tahapan, yaitu:

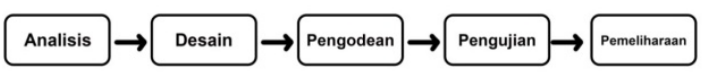

Gambar 1. Metode Waterfall

Keterangan pada Gambar 1:

1. Analisis

Dari permasalah pada clinix shoes yaitu banyaknya waktu yang digunakan untuk costumer dalam mengecek status sepatu dengan harus ke toko terlebih dahulu untuk mengetahui sepatunya sudah selesai dilaundry atau belum selesai, adapun opsi lain menggunakan media aplikasi Chatting.

Dengan adanya sistem tracking ini memudahkan para costumer untuk melakukan pengecekan status sepatu yang sedang mereka laundry,apakah sudah selesai atau belum. Dengan menginputkan resi yang diberi pihak laundry costumer bisa langsung mengecek status sepatunya.Hal ini mengantisipasi keterlambatan admin membalas pesan jika menggunakan aplikasi chatting biasa.

Sistem ini juga terdapat fitur cek tarif laundry,fitur ini dibuat untuk para costumer yang ingin melaundry sepatu tapi tidak mengetahui tarif 
dan malu untuk bertanya langsung ke toko jika tarifnya melebihi perhitungannya. Untuk mengetahui tarif laundry Costumer hanya menginputkan jenis sepatu dan treatment apa yang ingin dilakukan.

2. Desain

Desain merupakan proses multi langkah yang fokus pada desain pembuatan program sistem tercantum struktur informasi, arsitektur sistem, representasi antarmuka, serta prosedur pengodean.

Sesi ini mentranslasi kebutuhan sistem dari sesi analisis kebutuhan ke representasi desain supaya bisa diimplementasikan jadi program pada sesi berikutnya.

3. Pengodean

Pada sesi pengodean, desain wajib ditranslasikan ke dalam program sistem. Hasil dari sesi ini merupakan program pc cocok dengan desain yang sudah terbuat pada sesi desain.

4. Pengujian

Sesi pengujian fokus pada sistem dari segi logika serta fungsional serta membenarkan kalau seluruh bagian telah diuji. Perihal ini dicoba buat meminimalisir kesalahan( error) serta membenarkan keluaran yang dihasilkan cocok dengan yang diinginkan.

5. Pemeliharaan

Tidak menutup kemungkinan suatu sistem mengalami pergantian pada saat dikirimkan ke user. Pergantian dapat terjalin sebab terdapatnya kesalahan yang timbul serta tidak ditemukan dikala pengujian ataupun sistem wajib menyesuaikan diri dengan area baru. Sesi pemeliharaan bisa mengulangi proses pengembangan mulai dari analisis spesifikasi buat pergantian sistem yang telah terdapat, tetapi tidak buat sistem baru.

\section{HASIL DAN PEMBAHASAN}

User interface aplikasi yang dirancang berisi fitur login,cek status sepatu, input data costumer, cek tarif laundry. User interface sistem tracking ini menghasilkan sebuat bentuk visual secara umum, yang nantinya diharapkan pengalaman pengguna yang baik.

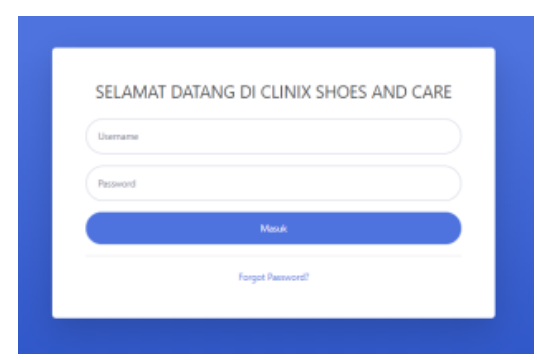

Gambar 2. Menu Login Admin.
Pada gambar 2 menu login hanya dapat diakses oleh admin, disini costumer tidak dapat melakukan login. Admin harus login terlebih dahulu untuk dapat makukan input data costumer.

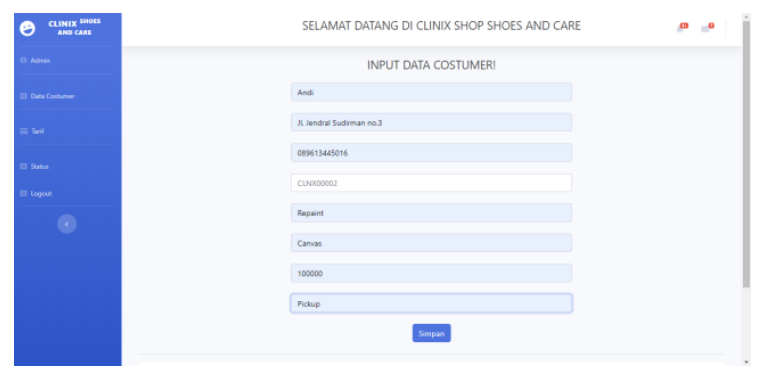

Gambar 3. Menu Input Data Costumer.

Pada gambar 3 Antarmuka Halaman Admin saat mengiputkan data costumer yang akan melakukan laundry sepatu. Setelah data berhasil di inputkan maka data tersebut otomatis akan tampil di halaman admin di menu data costumer.

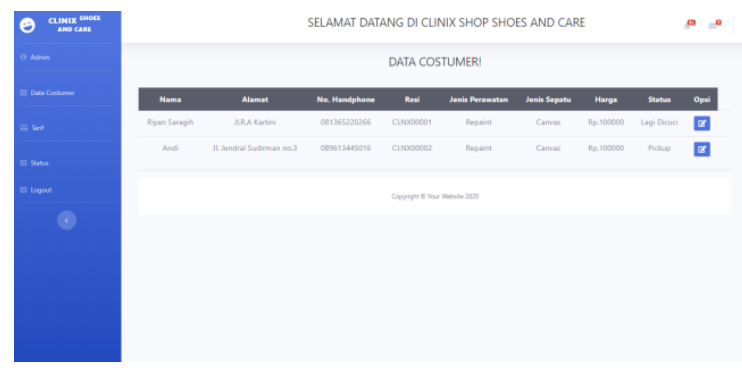

Gambar 4. Menu Data Costumer.

Pada gambar 4 halaman menu data costumer menampilkan data dari costumer yang melakukan laundry, dimana admin dapat melihat dan juga mengupdate data costumer dari menu tersebut

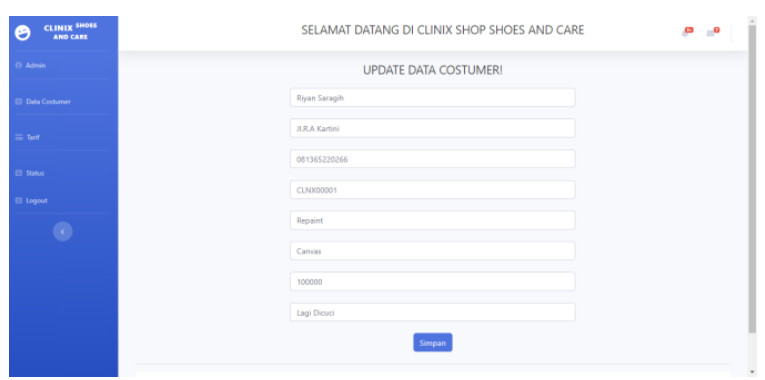

Gambar 5. Update Data Costumer.

Pada gambar 5 merupakan halaman update data costumer, pada menu ini admin dapat melakukan update data dari costumer yang ada di database untuk memperbaharui status laundry costumer. Di menu update ini data yang akan di update akan mencul kemudia setelah admin merubah salah satu yang ada 
diform tersebut maka admin dapat menyimpannya kembali, maka secara otomatis data akan berubah.

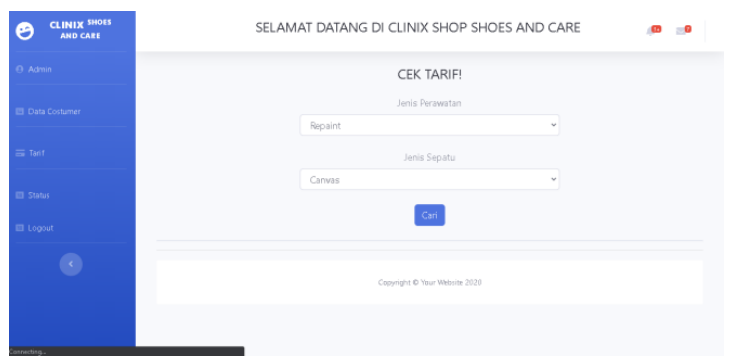

Gambar 6. Menu Cek Tarif Admin

Pada gambar 6 menampilkan halaman untuk melakukan pengecekan tarif untuk segala jenis perawatan yang tersedia. Admin menginputkan jenis perawatan dan jenis sepatu dan jika di tekan tombol cari maka sistem akan mencari data yang sesuai dengan database.

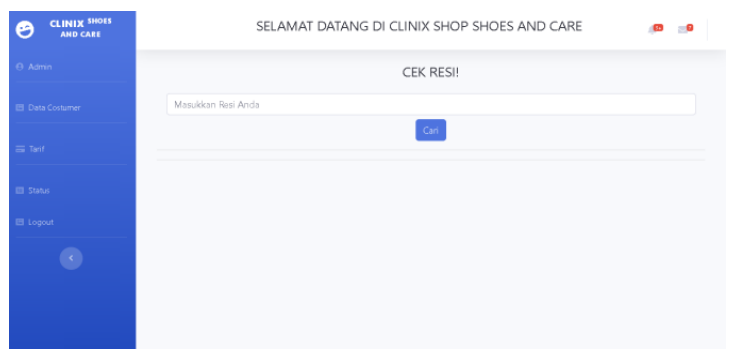

Gambar 7. Menu Cek Resi Admin

Pada gambar 7 menjelaskan tampilan halaman cek resi oleh admin, dimana admin harus menginputkan resi costumer untuk mengetahui status dari sepatu costumer tersebut.

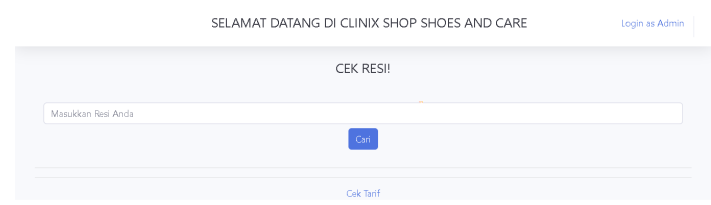

Gambar 8. Menu Cek Resi Costumer

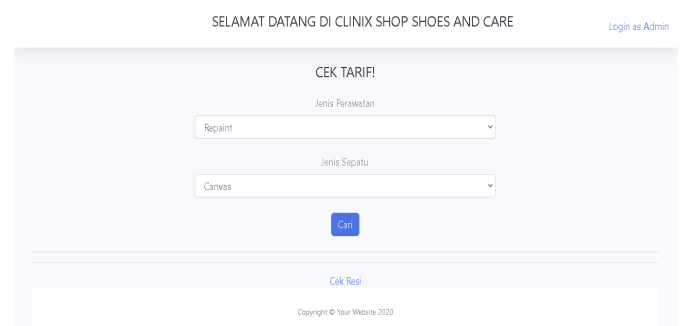

Gambar 9. Menu Cek Tarif Costumer

Pada gambar 8 dan 9 menjelaskan tampilan halaman cek resi dan cek tarif oleh costumer.

\section{KESIMPULAN} ini yaitu:

Kesimpulan yang dapat didapat dari penelitian

1. Costumer dapat melakukan pengecekan sepatu tanpa harus datang ke toko.

2. Costumer dapat melakukan pengecekan tarif tanpa harus datang ke toko.

3. Mempermudah admin dalam pendataan costumer.

\section{DAFTAR PUSTAKA}

Ahmad, A. (2012). Perkembangan Teknologi Komunikasi Dan Informasi. Jurnal Dakwah Tabligh, 13(1), 137-149.

Andriansyah, D. (2018). Penerapan Model Waterfall Pada Sistem Informasi Layanan Jasa Laundry Berbasis Web. Indonesian Journal on Software Engineering (IJSE), 4(1), 27-32.

Blanco, J. A., \& Upton, D. (2009). Improve your PHP coding productivity with the free compact open source MVC CodeIgniter framework. Birmingham: PacktPublishing Ltd.

Sitanggang, D. Y., Magdalena, L., \& Martha, D. (2017). Aplikasi Sistem Pengecekan Tarif dan Tracking Status Pengiriman Barang Menggunakan Ponsel Berbasis Java (Studi Kasus: PT. JNE Cirebon). Jurnal Digit, 4(2), 122-135.

Yulisar, A. A. (2019). Sistem Informasi Pelayanan Jasa Laundry Sepatu Pada Shoes Cleaning Majalengka. Universitas Komputer Indonesia. 